\title{
Resistencia química del hormigón XXV. Influencia de la adición de escoria a un cemento portland. Estudio de la concentración iónica del sistema cemento 3 /escoria-agua potable filtrada
}

\author{
DEMETRIO GASPAR-TEBAR Y JOSE LUIS SAGRERA-MORENO
}

\section{RESUMEN}

En el presente trabajo, continuación de otros, se estudia la variación del $\mathrm{pH}$, así como de la concentración de los iones $\mathrm{Ca}$ (II) y $\mathrm{SO}_{4}$ (II) del agua potable filtrada en donde han estado sumergidas las series de probetas de mortero $(1: 3)$ hechas con un cemento portland (cemento $3<>$ $<>P-450)$ y con las mezclas cemento 3/escoria $=$ $=85 / 15-65 / 35-40 / 60$ y $30 / 70$, en peso, durante el período de curado (21 días) y, posteriormente, durante 56 - 90 - 180 y 360 días (períodos de conservación), en esta etapa. Así mismo, se estudia la composición química de las nuevas fases sólidas formadas en dichos medios. La composicion estructural de dichas fases sólidas (calcita) se determinó por DRX, de ello se dió cuenta en (2).

En los distintos casos estudiados se ha puesto de manifiesto que se produce un incremento del contenido de Ca (II) en la disolución y en las nuevas fases sólidas, asi como del valor del $\mathrm{pH}$, que dependen de la mezcla utilizada para fabricar las diversas series de probetas y del tiempo de conservación. Las cantidades de $\mathrm{Ca}$ (II) en la disolución son, en la mayoría de los casos menores de $0,1 \times 10^{-2}$ moles, mientras que en las nuevas fases sólidas son mayores, llegando a alcanzar valores de $4,31 \times$ $\times 10^{-2}$ moles.

Por el contrario, el ion $\mathrm{SO}_{4}$ (II) no se ha detectado en las mencionadas fases sólidas, encontrándose en pequeñas cantidades en las diversas fases líquidas (agua potable filtrada); los mayores contenidos corresponden a los medios de las mezclas que tienen las mayores cantidades de escoria (60 y $70 \%$, en peso).

\begin{abstract}
SUMMARY
This work, which follows on others, study the variation of the $\mathrm{pH}$, and likewise the concentrations of the ions $\mathrm{Ca}(\mathrm{II})$ and $\mathrm{SO}_{4}$ (II) of the filtered potable water in which there were submerged the test specimens of mortar (1:3) made with a Portland cement (cement $3<>P-450$ ) and with the mixtures cement $3 / \mathrm{slag}=85 / 15-65 / 35-40 / 60$ and $30 / 70$ of weight, submerged for a curing period (21 days) and later during $56-90-180$ and 360 days (conservation periods), in this stage. It also study the chemical composition of the new solid phases formed in the said means. The structural composition of the solid phases (calcite) was determined by DRX; an account of this was given in (2).
\end{abstract}

In the different studied cases it has been demonstrated that an increase of the content of $\mathrm{Ca}$ (II) in the solution and in the new solid phases and of the value of the $\mathrm{pH}$ is produced, which depends on the mixture used to manufacture the different test specimen series and on the time of conservation. The cnotent of $\mathrm{Ca}$ (II) in the solution is less than $0,1 \times 10^{-2}$ moles, in most of the cases, while in the new solid phases is greater, reaching $4,31 \times 10^{-2}$ moles.

On the contrary, the ion $\mathrm{SO}_{4}$ (II) has not been in the solid phases mentioned, being found in little quantities in the different liquid phases (filtered potable water); the greater contents correspond to the means of the mixture that have the greater mounts of slag (60 and $70 \%$ of weight).

\section{INTRODUCCION}

En otros trabajos anteriores (1) (2) (3) se estudió:

a) La evolución que experimenta la resistencia química por el método de Koch-Stejnegger y las modificaciones sufridas por las resistencias mecánicas a flexotracción de las probetas de mortero $(1: 3)$ de $1 \times$ $\times 1 \times 6 \mathrm{~cm}$ hechas con el cemento portland (cemento $3<>$ P-450), objeto del presente artículo, y con las mezclas ce- mento 3/escoria $=85 / 15-65 / 35-40 / 60$ y $30 / 70$, en peso, sumergidas en agua potable filtrada $\left(^{\star}\right)$, unas series de 12 probetas, y en agua de mar artificial ASTM D

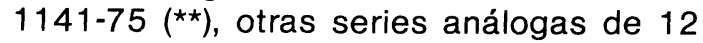
probetas, durante $56-90-180$ y 360 días, en esta etapa, después de haberlas curado 24 horas en un recinto saturado de humedad y, a continuación, bajo agua potable filtrada durante 21 días (1).

(*) Sistema: cemento 3/escoria-agua potable filtrada

$\left.{ }^{\star \star \star}\right)$ Sistema: cemento 3/escoria-agua de mar artificial. 
b) La composición estructural de las nuevas fases sólidas formadas en los medios de curado y de conservación (agua potable filtrada) (2), así como de conservación-ataque (agua de mar artificial ASTM) (3), en donde han estado sumergidas las mencionadas series de probetas de mortero.

c) La evolución de las características estructurales de la fracción enriquecida (cemento 3 hidratado y cemento 3 hidratado-atacado) extraída de uno de los prismas de cada serie de probetas de mortero de los sistemas cemento 3/escoria-agua potable filtrada (2) y cemento 3/escoria-agua de mar artificial ASTM (3).

En el presente artículo, continuación de los anteriores y que se ampliará con otros, se estudia la variación de la concentración de los iones calcio y sulfato en los medios de curado y de conservación (agua potable filtrada) en donde han estado sumergidas las diversas series de probetas de mortero, así como de las fases sólidas formadas, y la evolución del $\mathrm{pH}$ en dichos medios.

\section{PARTE EXPERIMENTAL}

Con el fin de conocer la variación de la concentración de los iones calcio y sulfato, así como del $\mathrm{pH}$, del agua potable filtrada en donde han estado sumergidas las probetas de mortero $(1: 3)$, hechas con cemento 3 y con las mezclas cemento $3 /$ escoria $=85 / 15-65 / 35$ - 40/60 y 30/70 (en peso), durante el período de curado (21 días) y de conservación $(56,90$, 180 y 360 dias) se ha separado, en una primera etapa, la fase sólida formada, que se ha secado en una corriente de nitrógeno; posteriormente, se ha determinado en la fase líquida la concentración de los iones mencionados y el valor del $\mathrm{pH}$.

En la nueva fase sólida, puesta en disolución por ataque con una disolución de ácido clorhídrico diluido $(1+1)$, se han determinado los contenidos de $\mathrm{Ca}$ (II) y de $\mathrm{SO}_{4}$ (II).

El contenido de los iones calcio se ha determinado complexométricametne con EDTA, el de los iones sulfato gravimétricamente al estado de sulfato de bario, y el valor del $\mathrm{pH}$ por medio de un $\mathrm{pH}$-metro, marca Crison, modelo 501.

De los materiales utilizados y características (cemeto 3 , escoria y arena), de la técnica operatoria seguida para preparar las mezclas de cemento 3 y escoria, así como para curar y conservar las probetas de mortero de las diversas series en agua potable filtrada se dió cuenta en (1).

\section{RESULTADOS OBTENIDOS}

\subsection{Período de curado}

En la tabla 1 se encuentran las cantidades de $\mathrm{Ca}$ (II), en moles $\times 10^{-2}$, que se han encontrado en la fase líquida (agua potable filtrada) en donde han estado sumergidas -durante el período de curado (21 días) - las diversas series de probetas de mortero, y el valor del $\mathrm{pH}$; así mismo, figuran las cantidades del mencionado ion correspondientes a las nuevas fases sólidas formadas en estas condiciones. En dicha tabla se puede apreciar que, prácticamente, todo el $\mathrm{Ca}$ (II) se encuentra en las fases sólidas, formando parte de la calcita (2).

TABLA 1

Sistema: cemento 3/escoria-agua potable filtrada.

Evolución de los contenidos de Ca (II) y del pH durante el período de curado (21 días)

\begin{tabular}{|c|c|c|c|c|}
\hline \multirow{2}{*}{$\begin{array}{c}\text { Mezcla: } \\
\text { cemento 3/es- } \\
\text { coria } \\
\text { (en peso) }\end{array}$} & $\begin{array}{c}|c| \\
\text { Ca (II); moles } \times 10^{-2} \\
\text { líquida } \\
\text { (Diso- } \\
\text { lución }\end{array}$ & $\begin{array}{c}\text { Fase } \\
\text { Solida }\end{array}$ & Suma & \\
\hline $100 / 0$ & $0,00_{4}$ & 1,09 & $1,09_{4}$ & 9,8 \\
$85 / 15$ & $0,00_{2}$ & 0,67 & $0,67_{2}$ & 9,8 \\
$63 / 35$ & $0,00_{1}$ & 0,65 & $0,65_{1}$ & 9,9 \\
$40 / 60$ & $0,00_{3}$ & 0,68 & $0,68_{3}$ & 9,6 \\
$30 / 70$ & $0,00_{3}$ & 1,08 & $1,08_{3}$ & 9,5 \\
\hline
\end{tabular}

El contenido de $\mathrm{Ca}$ (II) en el agua potable filtrada en donde se han curado las diversas series de probetas de mortero es menor que el del agua potable filtrada original $(0,005$ $\mathrm{g} / \mathrm{l}<>0,002_{5} \mathrm{~g} / \mathrm{l} 500 \mathrm{ml}<>0,00_{6} \times 10^{-2}$ moles), mientras que el correspondiente a las nuevas fases sólidas es mayor.

En la figura 1, en donde también se han representado las cantidades teóricas de $\mathrm{Ca}$ (II) que aportarían las mezclas cemento 3/escoria utilizadas en la fabricación de las probetas - calculadas a partir del $\mathrm{Ca}$ (II) puesto en juego por las probetas hechas sólo con cemento, suponiendo inerte a la escoria-, se aprecia que las cantidades experimentales de $\mathrm{Ca}$ (II) disuelto [Ca (II) en la fase sólida + $\mathrm{Ca}$ (II) en la disolución] correspondientes a los medios de curado de las series de probetas fabricadas con las mezclas que tienen el $60 \%$ y el $70 \%$ de escoria son superiores a los valores téricos. 


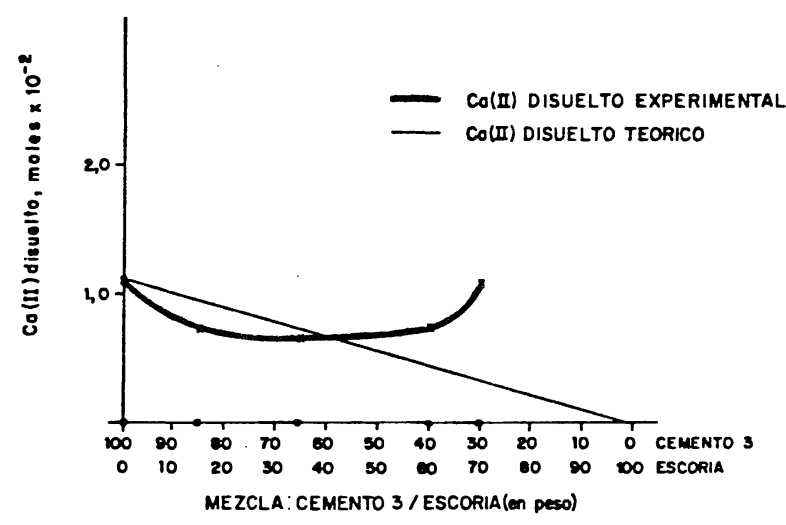

Fig. 1.-Sistema: cemento 3/escoria-agua potable filtrada. Período de curado: 21 días.

Evolución del contenido de $\mathrm{Ca}$ (II) en la disolución más en la fase sólida.

El $\mathrm{pH}$ del agua potable filtrada $(7,4)$ se ha incrementado en todos los casos, alcanzando los valores más altos en los medios en donde han estado sumergidas las probetas de mortero hechas con cemento 3 y con las mezclas que tienen 15 y $35 \%$ de escoria (en peso).

La nueva fase sólida formada, impurificada a veces por pequeñas fracciones desprendidas de las probetas de mortero (2), sigue una evolución análoga a las cantidades de $\mathrm{Ca}$ (II) de dicha fase sólida.

\subsection{Período de conservación}

En el medio (agua potable filtrada) en donde han estado sumergidas las distintas series de probetas de mortero, después del periodo de curado, durante 56 - 90 - 180 y 360 días se ha producido un incremento de la concentración de iones calcio y sulfato (suave), así como del valor del $\mathrm{pH}$, habiéndose formado una nueva fase sólida, que está constituída por el compuesto cristalino calcita, como se probó en (2).

En la tabla 2 figuran los resultados obtenidos, para cada edad y para cada serie de probetas de mortero, correspondientes a las nuevas fases sólidas formadas [cantidad, compuestos cristalinos identificados por DRX, contenidos de $\mathrm{Ca}$ (II) y de $\mathrm{SO}_{4}$ (II)] y a las disoluciones - agua potable filtrada- $[\mathrm{pH}$, contenidos de $\mathrm{Ca}$ (II) y de $\mathrm{SO}_{4}$ (II)] en donde se han conservado dichas series de probetas; resultados que se han representado en las figuras $2,3,4$ y 5 .

\section{Evolución de la fase sólida}

En las figuras 2 y 3 se ha representado la evolución de la fase sólida en función de la mezcla cemento 3 /escoria utilizada para fabri-
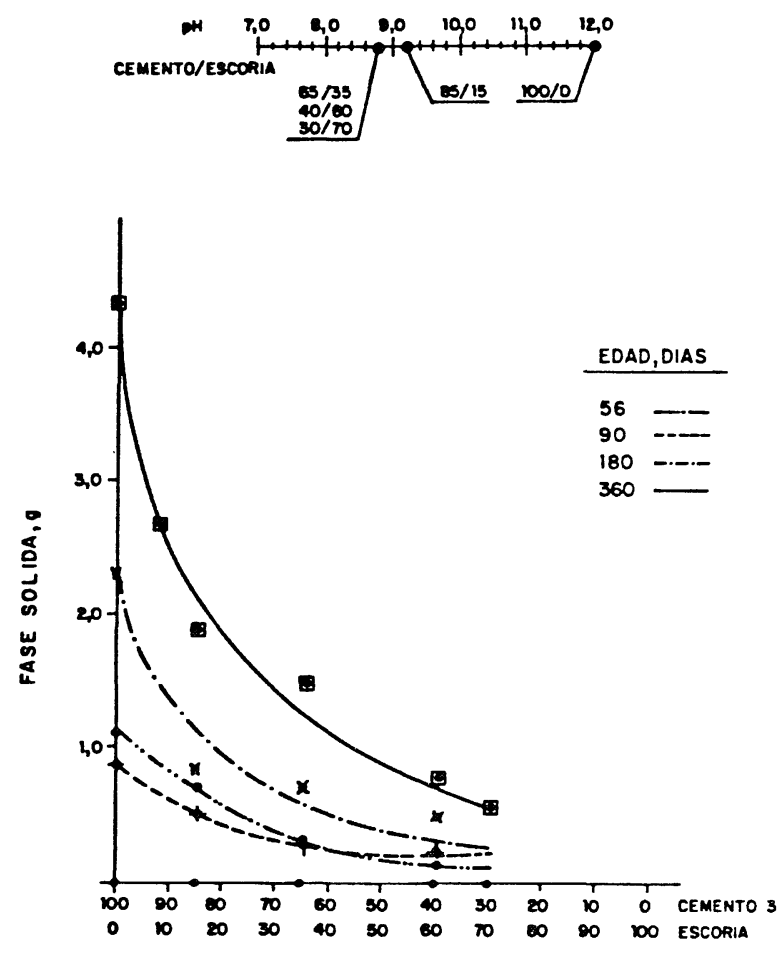

MEZCLA:CEMENTO 3/ESCORIA (en PESO)

Fig. 2.-Sistema: cemento 3/escoria-agua potable filtrada. Periodo de conservación: 56 - 90 - 180 y 360 días. Evolución de la cantidad de fase sólida y del pH.

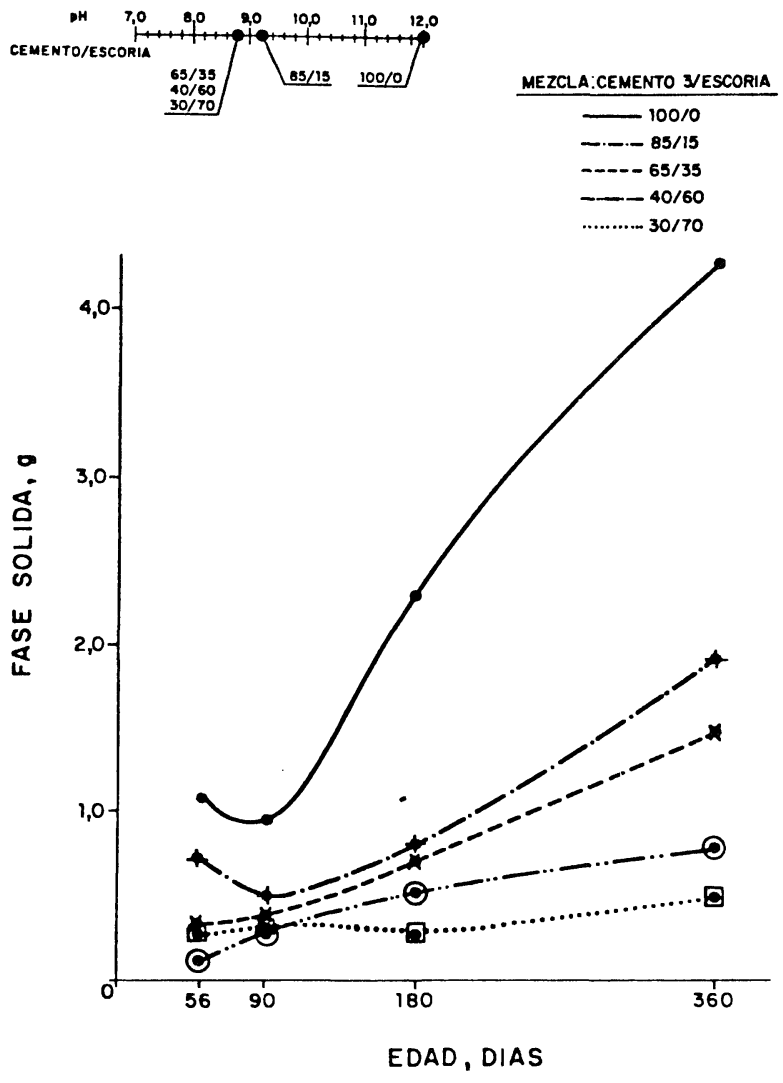

Fig. 3.-Sistema: cemento 3/escoria-agua potable filtrada. Período de conservación: 56 - 90 - 180 y 360 días. Evolución de la cantidad de fase sólida y del pH. 
car las diversas series de probetas de mortero para cada edad, en la primera, y del tiempo de conservación para cada mezcla, en la segunda.

La cantidad de fase sólida es, para cada edad, función de la mezcla utilizada en la fabricación de las distintas series de probetas de mortero (figura 2), experimentando una disminución conforme lo hace la cantidad de cemento 3 en la mezcla, o aumenta la de escoria; esta disminución es más acentuada según aumenta el tiempo de conservación, llegando a ser exponencial. Dicha cantidad de fase sólida, para cada mezcla, depende del tiempo de conservación (figura 3), aumentando, por regla general, conforme lo hace la edad.

Los incrementos experimentados en la fase sólida formada en los medios en donde han estado sumergidas las probetas de mortero durante 360 dias, con relación a la correspon- diente para 56 días, han sido 3,27 - 0,21 - 0,10 - 0,67 y 0,14 g para las series hechas con cemento 3 y con las mezclas cemento $3 /$ escoria $=85 / 15-65 / 35-40 / 60$ y $30 / 70$ (en peso), respectivamente.

\section{Evolución del contenido de Ca (II)}

En las figuras 4 y 5 se ha representado la evolución del contenido de $\mathrm{Ca}$ (II) que existe en la disolución y en la nueva fase sólida [Ca (II) procedente de los compuestos del cemento disueltol, junto con el $\mathrm{Ca}$ (II) presente en los $800 \mathrm{ml}$ de agua potable filtrada $(0,01 \times$ $\times 10^{-2}$ moles) en donde ha estado sumergida cada serie de probetas, en función de la mezcla cemento 3/escoria utilizada para fabricar las distintas series de probetas de mortero, primera figura, y del tiempo de conservación, segunda figura.

TABLA 2

Sistema: cemento 3/escoria-agua potable filtrada.

Evolución de la fase sólida formada, del $\mathrm{pH}$ y de los contenidos de $\mathrm{Ca}$ (II) y de $\mathrm{SO}_{4}$ (II)

\begin{tabular}{|c|c|c|c|c|c|c|c|c|c|c|}
\hline \multirow{2}{*}{$\begin{array}{l}\text { Cemen- } \\
\text { to } 3 / \text { es- } \\
\text { coria (en } \\
\text { peso) }\end{array}$} & \multirow{2}{*}{$\begin{array}{l}\text { Edad } \\
\text { días }\end{array}$} & \multicolumn{2}{|c|}{ Fase sólida } & \multirow{2}{*}{$\begin{array}{c}\text { Disolu- } \\
\text { cion } \\
\text { pH }\end{array}$} & \multicolumn{3}{|c|}{$\mathrm{Ca}$ (II); moles $\times 10^{-2}$} & \multicolumn{3}{|c|}{$\mathrm{SO}_{4}$ (II); moles $\times 10^{-2}$} \\
\hline & & $\mathbf{g}$ & DRX & & $\begin{array}{l}\text { Disolu- } \\
\text { ción }\end{array}$ & $\begin{array}{l}\text { Fase } \\
\text { sólida }\end{array}$ & Suma & $\begin{array}{l}\text { Diso- } \\
\text { lución }\end{array}$ & $\begin{array}{l}\text { Fase } \\
\text { sólida }\end{array}$ & Suma \\
\hline $100 / 0$ & & 1,07 & Calcita & 12,6 & 0,41 & 1,03 & 1,44 & $0,00_{1}$ & n.d. & $0,00_{1}$ \\
\hline $85 / 15$ & & 0,72 & $"$ & 10,3 & 0,01 & 0,70 & 0,71 & $0,00_{1}$ & n.d. & $0,00_{1}$ \\
\hline $65 / 35$ & 56 & 0,34 & $"$ & 8,8 & 0,02 & 0,32 & 0,34 & $0,00_{5}$ & n.d. & $0,00_{5}$ \\
\hline $40 / 60$ & & 0,15 & $"$ & 8,6 & 0,04 & 0,14 & 0,18 & $0,01_{5}$ & n.d. & $0,01_{5}$ \\
\hline $30 / 70$ & & 0,36 & $"$ & 8,7 & 0,05 & 0,34 & 0,39 & $0,01_{3}$ & n.d. & $0,01_{3}$ \\
\hline $100 / 0$ & & 0,90 & Calcita & 12,7 & 1,02 & 0,85 & 1,87 & $0,00_{1}$ & n.d. & $0,00_{1}$ \\
\hline $85 / 15$ & & 0,54 & $"$ & 9,0 & 0,02 & 0,52 & 0,54 & $0,00_{3}$ & n.d. & $0,00_{3}$ \\
\hline $65 / 35$ & 90 & 0,38 & $"$ & 8,6 & 0,02 & 0,36 & 0,38 & $0,00_{9}$ & n.d. & $0,00_{9}$ \\
\hline $40 / 60$ & & 0,29 & $"$ & 8,6 & 0,04 & 0,27 & 0,31 & $0,02_{8}$ & n.d. & $0,02_{8}$ \\
\hline $30 / 70$ & & 0,31 & $"$ & 8,6 & 0,05 & 0,28 & 0,33 & $0,03_{1}$ & n.d. & $0,03_{1}$ \\
\hline $100 / 0$ & & 2,27 & Calcita & 11,9 & 0,14 & 2,20 & 2,34 & $0,00_{2}$ & n.d. & $0,00_{2}$ \\
\hline $85 / 15$ & & 0,80 & $"$ & 9,3 & 0,19 & 0,77 & 0,96 & 0,01 & n.d. & 0,01 \\
\hline $65 / 35$ & 180 & 0,29 & $"$ & 9,1 & 0,02 & 0,72 & 0,74 & $0,02_{5}$ & n.d. & $0,02_{5}$ \\
\hline $40 / 60$ & & 0,51 & $"$ & 8,5 & 0,05 & 0,49 & 0,54 & $0,06_{1}$ & n.d. & $0,06_{1}$ \\
\hline $30 / 70$ & & 0,20 & $"$ & 8,7 & 0,07 & 0,19 & 0,26 & $0,07_{8}$ & n.d. & $0,07_{8}$ \\
\hline $100 / 0$ & & 4,34 & Calcita & 8,7 & 0,03 & 4,31 & 4,34 & $0,00_{4}$ & n.d. & $0,00_{4}$ \\
\hline $85 / 15$ & & 1,93 & $"$ & 8,3 & 0,01 & 1,92 & 1,93 & $0,01_{2}$ & n.d. & $0,01_{2}$ \\
\hline $65 / 35$ & 360 & 0,31 & $"$ & 8,5 & 0,04 & 1,41 & 1,45 & $0,09_{2}$ & n.d. & $0,09_{2}$ \\
\hline $40 / 60$ & & 0,77 & $"$ & 8,3 & 0,09 & 0,73 & 0,82 & $0,12_{8}$ & n.d. & $0,12_{8}$ \\
\hline $30 / 70$ & & 0,50 & $"$ & 8,2 & 0,16 & 0,49 & 0,65 & 0,16 & n.d. & 0,16 \\
\hline
\end{tabular}

n.d. $=$ no detectado. 


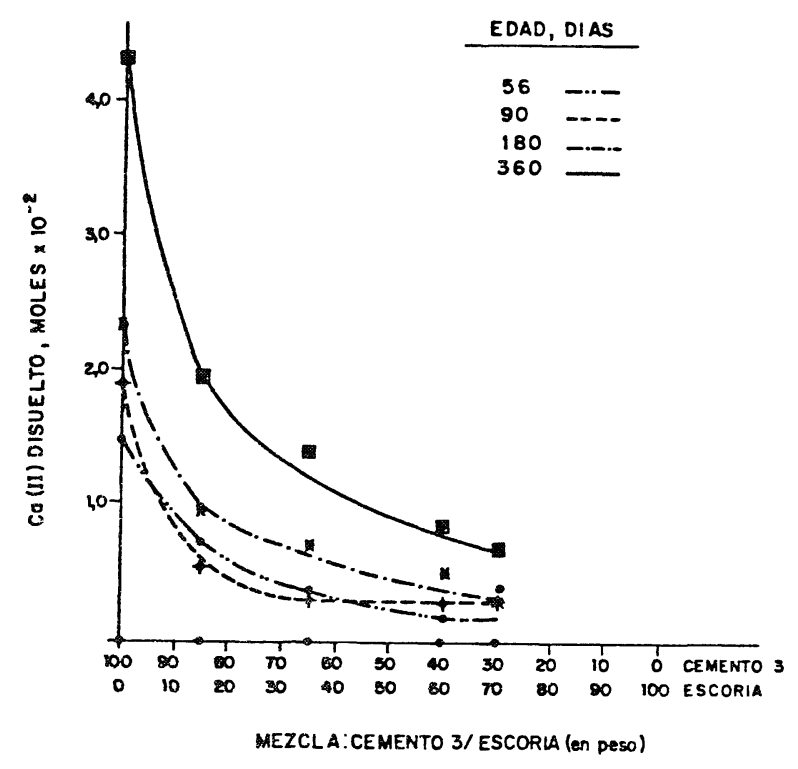

Fig. 4.-Sistema: cemento $3 /$ escoria-agua potable filtrada. Período de conservación: 56 - 90 - 180 y 360 días. Evolución del contenido de $\mathrm{Ca}$ (II) en la disolución más en la fase sólida.

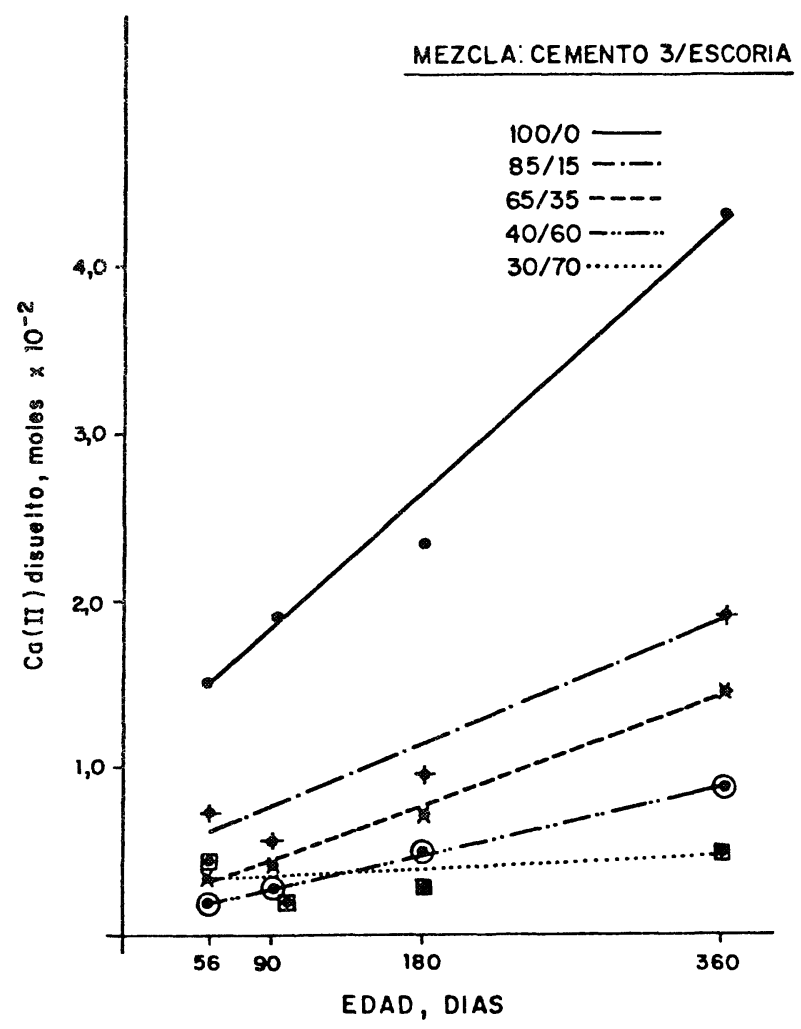

Fig. 5.-Sistema: cemento 3/escoria-agua potable filtrada. Período de conservación: 56 - 90 - 180 y 360 dias. Evolución del contenido de $\mathrm{Ca}$ (II) en la disolución más en la fase sólida.

Las cantidades de $\mathrm{Ca}$ (II) en las disoluciones en donde han estado sumergidas las diversas series de probetas de mortero son, por regla general, superiores a $0,01 \times 10^{-2}$ moles y menores de $0,1 \times 10^{-2}$ moles. En los casos de los medios en donde han estado las series de probetas hechas con cemento 3 /escoria $=$ $=85 / 15$ (en peso) -para $t=22+56$ dias y $t=22+360$ dias - son iguales a $0,01 \times 10^{-2}$ moles, mientras que para los medios correspondientes a las series elaboradas con las mezclas cemento $3 /$ escoria $=100 / 0$ (en peso) - para $t=22+56$ dias, $t=22+90$ dias y $t=22+180$ días-; 85/15 (en peso) -para $t=22+180$ días - y 30/70 (en peso) - para $t=22+360$ días - son mayores de $0,1 \times 10^{-2}$ moles.

En la figura 4 se observa que dicha cantidad de $\mathrm{Ca}$ (II) total [Ca (II) en la disolución + $\mathrm{Ca}$ (II) en la nueva fase sólida] es función, para cada edad, de la mezcla utilizada para fabricar las distintas series de probetas de mortero, habiendo experimentado una disminución conforme lo hace el contenido de cemento 3 en dichas mezclas. Esta disminución es tanto más acentuada conforme aumenta el tiempo de conservación (tabla 2 ); así, pasa de $1,44 \times 10^{-2}$ moles a $0,39 \times 10^{-2}$ moles para $t=22+56$ dias y de $4,34 \times 10^{-2}$ moles a $0,65 \times 10^{-2}$ moles para $t=22+360$ días, según se trate de los medios en donde han estado sumergidas las probetas de mortero hechas con las mezclas cemento $3 /$ escoria $=100,0$ y $30 / 70$ (en peso), respectivamente. La evolución del mencionado contenido de $\mathrm{Ca}$ (II) está íntimamente ligada a la cantidad de la nueva fase sólida formada (figura 2).

En la figura 5 se aprecia que las cantidades de $\mathrm{Ca}$ (II) que existen en la disolución más en la nueva fase sólida, correspondientes a los medios en donde han estado sumergidas las diversas series de probetas de mortero, fabricadas con cemento 3 y con las mezclas cemento 3 /escoria estudiadas, son función del tiempo de conservación para cada mezcla. Las mayores cantidades de $\mathrm{Ca}$ (II) puestas en juego corresponden, para todas las edades, a los medios en donde han estado sumergidas las probetas de mortero hechas con cemento $3 \mathrm{y}$ las menores para aquellos medios en donde se han conservado las series de probetas elaboradas con las mezclas cemento 3/escoria $=$ $=65 / 35-40 / 60$ y $30 / 70$ (en peso).

\section{Evolución del contenido de $\mathrm{SO}_{4}(\mathrm{II})$}

Los iones sulfato, únicamente, se han detectado en la disolución (agua potable filtrada) en donde han estado sumergidas las distintas series de probetas de mortero (tabla 2). El contenido de dichos iones en los medios en donde se han conservado dichas series de probetas, con relación al del agua potable filtrada $\left(0,002 \times 10^{-2}\right.$ moles en $\left.800 \mathrm{ml}\right)$ es ligeramente inferior para el caso de las probetas de mortero hechas con cemento $3 /$ escoria $=100 / 0$ (en peso) para $t=22+56$ dias y $22+90$ 
dias y $85 / 15$ (en peso) para $t=22+56$ días, $y$ del mismo orden para los medios en donde han estado durante 180 días las probetas de mortero fabricadas con cemento 3 y mayores en los casos restantes. Las mayores cantidades corresponden al agua potable filtrada en donde se han conservado las series de probetas, para todas las edades, elaboradas con las mezclas cemento $3 /$ escoria $=40 / 60$ y $30 / 70$ (en peso), que son del mismo orden entre ellas.

\section{INTERPRETACION DE RESULTADOS}

El Ca (II) presente en el agua potable filtrada, en donde han estado sumergidas las diversas series de probetas hechas con cemento $3 \mathrm{y}$ con las mezclas cemento 3/escoria estudiadas, así como en la nueva fase sólida formada en dicha agua potable filtrada procede, fundamentalmente, de la disolución del hidróxido de calcio generado en las reacciones de hidratación del cemento, según:

$$
\begin{aligned}
& \mathrm{Ca}(\mathrm{OH})_{2} \text {.sólido } \stackrel{\mathrm{H}_{2} \mathrm{O}}{\rightleftharpoons} \mathrm{Ca}(\mathrm{OH})_{2} \text {.disuelto } \stackrel{\mathrm{H}_{2} \mathrm{O}}{\rightleftharpoons} \mathrm{Ca}(\mathrm{II})+ \\
& +2 \mathrm{OH} \text { (I) }
\end{aligned}
$$

produciéndose, además, un aporte de la concentración de iones $\mathrm{OH}$ (I) y, por consiguiente, un aumento del valor del $\mathrm{pH}$.

La solubilidad del $\mathrm{Ca}(\mathrm{OH})_{2}$ en agua, a $20^{\circ} \mathrm{C}$, es $1,230 \mathrm{~g} / \mathrm{l}(4)<>1,66 \times 10^{-2}$ moles/litro $<>$ $<>1,33 \times 10^{-2}$ moles en $800 \mathrm{ml}$. Dicha cantidad se ha superado [Ca (II) en la disolución + Ca (II) en la fase sólida] en los medios en donde han estado sumergidas las probetas hechas con cemento 3, para todas las edades, y con la mezcla que tiene $15 \%$ y $35 \%$ de escoria (en peso) para $t=22+360$ días; en los casos restantes ha sido menor.

Los contenidos de $\mathrm{Ca}$ (II) en los distintos medios (agua potable filtrada) han sido, en la mayoría de los casos, menor de $0,1 \times 10^{-2}$ moles, habiendo precipitado el $\mathrm{Ca}$ (II) - procedente del $\mathrm{Ca}(\mathrm{OH})_{2}$ disuelto- como $\mathrm{CaCO}_{3}$ según la reacción (B), por lo que en estos medios puede continuar la reacción $(A)$ si se dan condiciones favorables $y$, por consiguiente, el avance de las reacciones de hidratación.

El $\mathrm{CO}_{2}$ disuelto en el agua reacciona, en medio básico fuerte, con el $\mathrm{Ca}$ (II) presente en la disolución, de acuerdo con la reacción $(\mathrm{B})$ :

$$
\begin{aligned}
& \mathrm{CO}_{2}+\mathrm{Ca}(\mathrm{II})+2 \mathrm{OH}(\mathrm{I}) \rightleftharpoons \\
& \rightleftharpoons \mathrm{CaCO}_{3} \text {. sólido }+\mathrm{H}_{2} \mathrm{O}
\end{aligned}
$$

Para que la reacción de carbonatación tenga lugar, en las condiciones de este sistema [elevada concentración de $\mathrm{OH}(\mathrm{I})$, cantidades de $\mathrm{Ca}$ (II) disueltas que oscilan entre $0,18 \times 10^{-2}$ moles $/ 800 \mathrm{ml}$ y $4,34 \times 10^{-2}$ moles $/ 800 \mathrm{ml}<>$ $<>0,23 \times 10^{-2}$ moles/litro y $5,43 \times 10^{-2}$ moles/litro], se debe cumplir:

$$
\text { [Ca (II)] }\left[\mathrm{CO}_{3}(\mathrm{II})\right]>\mathrm{P}_{\mathrm{s}}\left(4,8 \times 10^{-9}\right)
$$

por lo que, teóricamente, en estos casos se precisan para precipitar las mencionadas cantidades de $\mathrm{Ca}$ (II) de $21 \times 10^{-7}$ moles/litro a $0,88 \times 10^{-7}$ moles/litro de $\mathrm{CO}_{2}$.

La escoria, que existe en la mezcla utilizada para fabricar las probetas, fija parcialmente el $\mathrm{Ca}(\mathrm{OH})_{2}$ naciente formando compuestos de calcio, dando lugar a la disminución de unos y al incremento de otros; otra parte de dicho hidróxido de calcio se disuelve según el equilibrio (A). La cantidad de $\mathrm{Ca}(\mathrm{OH})_{2}$ disuelto depende de la mezcla utilizada, quedando el resto en las probetas en determinados casos, llegando a desaparecer, prácticamente, en otros (por formacion de nuevos compuestos con la escoria y por disolución en el agua potable filtrada) como sucede con las mezclas cemento $3 /$ escoria $=40 / 60$ y $30 / 70$ (en peso) para $t=22+360$ días, para las dos mezclas, y $t=22+180$ días, para la segunda mezcla (2).

La cantidad de fase sólida formada es función, para una misma edad, de la mezcla utilizada y, para una mezcla, del tiempo de conservación; esta cantidad depende del $\mathrm{Ca}(\mathrm{OH})_{2}$ disuelto, que está íntimamente ligada a la generada en las reacciones de hidratación y que no haya formado compuestos poco solubles en agua, más estables que el $\mathrm{Ca}(\mathrm{OH})_{2}$.

En los valores del $\mathrm{pH}$ influye la cantidad de $\mathrm{Ca}(\mathrm{OH})_{2}$ disuelto en el agua potable filtrada, por una parte, que proporciona los iones $\mathrm{OH}(\mathrm{I})$, y del grado de carbonatación, por otra, que en la reacción correspondiente consume dos moles de $\mathrm{OH}$ (I) por cada mol que se forme de $\mathrm{CaCO}_{3}$.

El incremento de la concentración de iones sulfato, que se ha producido en determinados casos y, fundamentalmente, en los medios en donde han estado sumergidas las diversas series de probetas de mortero que tienen los mayores contenidos de escoria (60\% y $70 \%$, en peso), procede de la disolución de los compuestos correspondientes que se encuentran en el cemento 3 hidratado (dicho cemento 3 tiene un contenido de $\mathrm{SO}_{4}$ (II) del $5,5 \%$, en peso) ya que en la escoria no se han detectado; hecho que se pretende demostrar en otros trabajos, como se señaló en (5) y en (6). 


\section{CONCLUSIONES}

\subsection{Periodo de curado}

\section{Primera:}

En el agua potable filtrada en donde han estado sumergidas las diversas series de probetas de mortero $(1: 3)$, hechas con cemento 3 y con las mezclas cemento 3 /escoria estudiadas en este trabajo, durante 21 días (período de curado), se ha producido un incremento de $\mathrm{Ca}$ (II) que, prácticamente, ha precipitado como $\mathrm{CaCO}_{3}$, en forma de calcita, dando lugar a una nueva fase sólida. Así mismo, se ha producido un aumento del valor del $\mathrm{pH}$.

Tanto las cantidades de $\mathrm{Ca}$ (II) mencionadas, como los valores del $\mathrm{pH}$, son función de la mezcla cemento 3/escoria utilizada en la fabricación de las probetas.

\subsection{Período de conservación}

\section{Segunda:}

En el agua potable filtrada en donde han estado sumergidas las diversas series de probetas de mortero, después del período de curado, durante 56 - 90 - 180 y 360 días, se produce un incremento de la concentración de iones calcio y sulfato (suave), así como del valor del $\mathrm{pH}$, apareciendo una nueva fase sólida, que está formada por el compuesto cristalino calcita.
Las cantidades de $\mathrm{Ca}$ (II) en la disolución, en donde se han conservado las probetas de mortero, es en la mayoría de los casos menor de $0,1 \times 10^{-2}$ moles, mientras que en la nueva fase sólida es mayor de dicha cantidad, llegando a alcanzar valores de 4,31 $\times 10^{-2}$ moles.

\section{Tercera:}

Tanto las cantidades de las nuevas fases sólidas, como las de $\mathrm{Ca}$ (II) en la disolución más en la fase sólida, son función de la mezcla utilizada en la fabricación de las probetas, para cada edad, y del tiempo de conservación, para cada mezcla. Dichas cantidades experimentan una disminución conforme lo hace la cantidad de cemento 3 en la mezcla y un incremento según aumenta el tiempo de conservación.

\section{Cuarta:}

Los iones sulfato no se han detectado en la nueva fase sólida y si en las disoluciones (agua potable filtrada) en donde han estado sumergidas las distintas series de probetas de mortero, habiendo experimentado un ligero incremento, con relación al contenido de dicho ion en el agua potable filtrada, en los medios correspondientes a las series de probetas fabricadas con las diversas mezclas cemento 3/escoria y, de un modo especial, con las mezclas que tienen las mayores cantidades de escoria (60 y $70 \%$, en peso).

\section{BIBLIOGRAFIA}

(1) SAGRERA-MORENO, J. L. y GASPAR-TEBAR, D. (1980): Resistencia química del hormigón: VIII. Acción del agua de mar: influencia de la adición de escoria a un cemento portland. Evolución de las resistencias mecánicas a flexotracción y del coeficiente de corrosión. Materiales de Construcción, octubre-noviembre-diciembre, 180, 99-120.

(2) GASPAR-TEBAR, D. y SAGRERA-MORENO, J. L. (1981): Resistencia química del hormigón: XII. Influencia de la adición de escoria a un cemento portland. Estudio por DRX del sistema cemento $3 /$ escoria-agua potable filtrada. Materiales de Construcción, julio-agosto-septiembre, 183, 33-44.

(3) GASPAR-TEBAR, D. y SAGRERA-MORENO, J. L. (1983): Resistencia química del hormigón: XX. Acción del agua de mar: influencia de la adición de escoria a un cemento portland. Estudio por DRX. Materiales de Construcción, abrilmayo-junio-julio-agosto-septiembre, 190-191, 3-24.

(4) BICZOK, I. (1972): Corrosión y Protección del Hormigón. Ed. Urmo. Bilbao, pág. 211.

(5) SAGRERA-MORENO, J. L. y GASPAR-TEBAR, D. (1983): Resistencia química del hormigón: XXI. Influencia de la adición de escoria a un cemento portland de alta resistencia inicial. Estudio de la concentración iónica del sistema cemento 1/escoria-agua potable filtrada. Materiales de Construcción, octubre-noviembre-diciembre, 192, 33-41.

(6) SAGRERA-MORENO, J. L. y GASPAR-TEBAR, D. (1984): Resistencia química del hormigón: XXIII. Influencia de la adición de escoria a un cemento portland resistente al yeso. Estudio de la concentración iónica del sistema cemento 2/escoria-agua potable filtrada. Materiales de Construcción, abril-mayo-junio, 194, 43-51.

\section{RECONOCIMIENTO}

Nuestro más sincero agradecimiento a las personas del Equipo de Durabilidad del IETcc: Amalia Rodríguez Pereira, Lucila López Solana, M. ${ }^{a}$ Soledad Cid Fernández y Felipe Cantero Palacios, por su valiosa colaboración en la realización de este trabajo. 